\title{
DÉCADA DE RECURSOS HUMANOS EM SAÚDE: 2006-2015
}

Isabel Amélia Costa Mendes ${ }^{1}$ Maria Helena Palucci Marziale ${ }^{2}$

( modelo competente de gestão de pessoas para a atualidade é aquele orientado para solucionar problemas, enfrentar os desafios da organização e apresentar resultados. Investimentos em recursos humanos devem focalizar a força intelectual, uma vez que a criação e a manutenção de vantagens competitivas sustentáveis dependem desse ativo.

A alta valorização de idéias, de respostas diversificadas, de inovação e de resultados esperados decorre da otimização da produtividade cerebral; assim, tem sido frenética a busca de talentos para atuarem em diferentes campos de trabalho. Por isso, hoje, os ativos organizacionais mais importantes são as pessoas.

No campo da saúde, deparamos com uma crise resultante de problemas relacionados a seus recursos humanos no que tange ao contexto e ao conteúdo do trabalho, ou seja: escassez, má distribuição, condições inadequadas de trabalho, conhecimento e competências limitados, estratégias equivocadas de gestão de recursos humanos face às realidades dos serviços e demandas da população, redundando em estresse, infelicidade e baixa auto-estima do trabalhador, aliados à assistência insuficiente e de qualidade muito questionada.

Está em curso um chamamento para ação imediata que dê conta de responder à crise e valorizar, investir e conferir poder aos recursos humanos da área da saúde. Esse movimento requer ampla participação e envolvimento no seu planejamento e ações estratégicos. E, certamente, deve ser adequado a contextos específicos.

Nessa perspectiva, a VII Reunião Regional dos Observatórios de Recursos Humanos em Saúde, realizada em Toronto, 2005, determinou que o período 2006-2015 se constitui em “Uma Década de Recursos Humanos em Saúde"(1).

Tal determinação se deve à necessidade de enfrentar os sérios desafios em relação ao desenvolvimento desses recursos na região das Américas.

Dentre as orientações estratégicas, foram incluídos temas referentes à formação e capacitação das pessoas; assim, destacaram-se as seguintes questões: fortalecimento das lideranças, maior valorização e investimento em recursos humanos, coordenação e integração das ações nos diversos âmbitos, manutenção de políticas e intervenções, empenho na oferta de informação mais qualificada para subsidiar a tomada de decisões $^{(1)}$.

Os desafios a serem superados abrangem a adoção de políticas e programas capazes de:

- alinhar as pessoas às mudanças nos sistemas de saúde;

- garantir sua distribuição eqüitativa e adequada;

- instituir mecanismos que regulem a migração de profissionais de saúde;

- promover interação entre as instituições de ensino e de serviço de saúde de modo que os recursos humanos em formação incorporem os valores, as atitudes e as competências do modelo de atenção universal fundamentado na qualidade e na eqüidade ${ }^{(1)}$.

Cabe, agora, a cada país da região das Américas concretizar as referidas orientações estratégicas para que se alcancem as Metas de Desenvolvimento do Milênio e para que até 2015 - final dessa década que prioriza os recursos humanos - toda população tenha acesso universal aos serviços qualificados de saúde.

Editores da Revista Latino-Americana de Enfermagem da Escola de Enfermagem de Ribeirão Preto, da Universidade de São Paulo, Centro Colaborador da OMS para o desenvolvimento da pesquisa em enfermagem: ${ }^{1}$ Diretor, Professor Titular, e-mail: iamendes@eerp.usp.br; ${ }^{2}$ Professor Associado, e-mail: marziale@eerp.usp.br 


\section{REFERÊNCI A BI BLI OGRÁFI CA}

1. Pan American Health Organization. [homepage on the internet]. Washington: PAHO; 2004. [cited 2006 January 20]. Observatory of Human Resources. [about 1 screen]. Available from: http://www.observatoriorh.org/Toronto/29SetAgenda_PT.pdf 